\title{
laborhiftórico
}

ISSN 2359-6910

https://revistas.ufrj.br/index.php/lh/

ARTIGO

Recebido em 28 de janeiro de 2020

Aprovado em 28 de abril de 2020

\section{Questões diacrônicas das Ciências do Léxico: a dicionarização de brasileirismos no campo semântico da fauna e flora}

\author{
Diachronic issues of the Lexicon Sciences: the dictionaryization \\ of brasileirisms in the semantic field of fauna and flora
}

DOI: https://doi.org/10.24206/lh.v6i3.31887

Manoel Messias Alves da Silva

Professor Associado Tide Nível C, da Área de Língua Portuguesa, do Departamento de Língua Portuguesa, do Centro de Ciências Humanas, Letras e Artes, da Universidade Estadual de Maringá/PR. Por meio da Resolução ${ }^{\circ}$ 119/2006-PLE, de 29/08/2006, passou a atuar também como Professor Permanente no Programa de Pós-Graduação em Letras (Mestrado e Doutorado), Área de Concentração em Estudos Linguísticos e Linha de Pesquisa em Descrição Linguística.

E-mail: mmasilva@uem.br ORCID: https://orcid.org/0000-0001-5261-4037

\section{Luana Vitoriano}

Doutoranda em Letras, pela Universidade Estadual de Maringá (UEM), tem Estudos Linguísticos por linha de pesquisa e Estudos do Texto e do Discurso área de concentração. Mestra em Linguística (2016) e graduada em Letras (2013) pela UEM. É também pesquisadora do Grupo de Estudos em Análise do Discurso (GEDUEM). 


\title{
RESUMO
}

Os estudos diacrônicos sobre o léxico possibilitam compreender a complexa relação entre língua, cultura, história e memória de um determinado povo. Tendo por base o enfoque temático dos "brasileirismos" na língua portuguesa e com o fim de estabelecer uma análise diacrônica do léxico definimos por objetivos: a) realizar uma explanação teórica sobre as questões diacrônicas nos estudos do léxico; b) discorrer sobre as origens do campo lexical relacionado à fauna e à flora; c) investigar os modos como essas (não) mudanças linguísticas estão atreladas ao contexto sociocultural do país. Nessa conjuntura, desenvolvemos uma pesquisa documental e comparativa sobre os verbetes selecionados para análise, de modo que os aspectos metodológicos versam sobre quatro aspectos gerais: i) seleção de corpora: seis dicionários; ii) definição temática do corpus: campo semântico relacionado à fauna e à flora brasileira; iii) recorte do corpus: investigação de cinco vocábulos do campo semântico selecionado em corpora; iv) prática analítica: contraste entre os vocábulos (aspectos semânticos e morfológicos). Para tanto, embasamo-nos nas perspectivas teóricas da Lexicologia e da Lexicografia (diacrônicas), em especial, nas contribuições de Krieger (2010) e Murakawa (2010).

Palavras-chave: Lexicologia. Mudanças linguísticas. Língua portuguesa. Brasileirismos. Diacronia.

\begin{abstract}
The diachronic studies on lexicon allow us to comprehend the complex relation among language, culture, history and memory of a given people. Having as theoretical basis the thematic focus of "Brazilianisms" in the Portuguese language, and as its specific objectives: a) perform an introductory theoretical explanation on the diachronic questions involving lexicon studies ; b) address the origins of the fauna and flora related lexicon; c) investigating the ways in which these linguistic (non) changes are imbued to the country's socio-cultural contexts. In this juncture, we have developed a documental and comparative research on the entries selected for this analysis, so that the methodological matters address four general aspects: i) Corpora selection: six dictionaries; ii) Thematic definition of the corpus: semantic field related to Brazilian fauna and flora; iii) Corpus narrowing: investigation of five words of the selected semantic field corpora; iv) Analytical practice: contrast among the words (semantic and morphological aspects). For this purpose, we have theoretically based ourselves in the Lexicographic and Lexicological Sciences (diachronic), in particular, in the contributions of Krieger (2010) and Murakawa (2010).
\end{abstract}

Keywords: Lexicology. Linguistic changes. Portuguese language. Brazilianisms. Diachronic. 


\section{Introdução}

As Ciências do Léxico preocupam-se com a totalidade das unidades lexicais de uma língua e as formas como esse conjunto de lexias pode ser organizado, se considerados os diversos aspectos que o circundam, como os históricos, geográficos, fonéticos, usos sociais e culturais, entre outros (ZAVAGLIA; WELKER, 2008). Por suas especificidades a Lexicologia possui ramificações, de acordo com seus principais objetivos, a saber: Lexicologia teórica (também conhecida por Metalexicografia) e Lexicologia prática. Essas são as subáreas da Linguística que investigam todos os pormenores constituintes das obras dicionarísticas.

Os dicionários, por sua vez, proporcionam um vasto registro lexical, pois são resultados de um minucioso trabalho de lexicólogos com e sobre a língua dita geral. Deste modo, este tipo de produção lexicográfica é capaz de representar "a língua e a cultura de uma coletividade” (SILVA, 2001, p. 284), bem como (deve) "acompanhar a sociedade, mudando com o tempo, as correntes ideológicas e os avanços tecnológicos” (SILVA, 2001, p. 284).

Para Haensch (1982), o fazer lexicográfico pode ser engendrado por meio de três dimensões divergentes e complementares entre si: a) o surgimento da Lexicografia, isto é, a história a qual os vocábulos e as próprias obras estão circunscritas; b) os campos existentes de pesquisa lexicográfica, em que se compreendem os estudos lexicográficos já realizados no país; c) as possibilidades de esboçar diretrizes gerais de análise, por meio de critérios teórico-linguísticos. Adotaremos o viés da Lexicografia histórica, para composição do trabalho, uma vez que urge a necessidade de compreender vocábulos da língua portuguesa no que tange à questão dos brasileirismos em consonância com os aspectos histórico e sociais involucrados à temática.

O viés teórico Lexicográfico que toma a história como ponto culminante de sua produção é conhecido por Lexicografia diacrônica. Tal perspectiva, nas Ciências do Léxico, permite identificar a diversidade linguística do país, visto que é possível distinguir os vocábulos que foram incorporados à língua, e aqueles que caíram em desuso, bem como verificar a presença multicultural e multilinguística a partir da análise etimológica dos vocábulos. O dicionário constitui-se, portanto, enquanto "um texto que fala da língua e da cultura, funcionando como um componente de expressão cultural e ideológica, tecido sob a aparência de catálogo de palavras" (KRIEGER, 2010, p. 136).

Propomos, neste estudo, esboçar um movimento analítico que priorize a perspectiva teórica diacrônica dos estudos do léxico, a fim de contrastar as mudanças linguísticas em um corpus composto por cinco verbetes do campo semântico da fauna e da flora presentes em dicionários de língua geral. Ponderamos que este tipo de pesquisa permite compor um panorama geral sobre o registro lexical e as 
modificações incorporadas às palavras e às suas significações no decorrer dos anos, criando-se, assim, a possibilidade de indicar as "grafias diferentes e as variações semânticas e morfológicas encontradas" (HAENSCH, 1982 apud MURAKAWA, 2010, p. 239).

Para tanto, o estudo de corpora contemplou cinco dicionários de língua portuguesa (doravante, LP). As produções eleitas foram as dos lexicólogos: Raphael Bluteau e seu Vocabulario Portuguez e Latino (1712); Antonio de Moraes e Silva e seu Diccionario da Lingua Portugueza (1789); Cândido de Figueiredo, com o Novo Diccionário da Língua Portuguesa Cândido de Figueiredo (1911); Caldas Aulete, com o Dicionário Contemporâneo da Língua Portuguesa (7 ed., de 1980); Priberam, denominado Dicionário Priberam da Língua Portuguesa (2008). Estas obras dicionarísticas nos permitem investigar as transformações ou não dos léxicos, pois abrange um período de quase trezentos anos de história da língua portuguesa no Brasil e proporciona dada compreensão diacrônica sobre a língua.

A Lexicologia e a Lexicografia possuem importância fundamental para o campo teórico e analítico da Linguística, tendo em vista que oferecem subsídios para se compreender os múltiplos deslocamentos morfológicos e semânticos do conjunto de palavras com as quais um povo vive, isto é, cria identidades e mantém relações de poder de toda ordem. Dentre as diversas contribuições dessa perspectiva teórica, podemos mencionar a catalogação das unidades lexicais, a conservação da memória linguística, a certificação da identidade linguística, a legitimação da língua, o estatuto de poder e a padronização de uma referência social do dizer (KRIEGER, 2010).

Desse modo, ressaltamos que o enfoque desta pesquisa será depreender as mudanças morfossemânticas, que ocorreram ou não nas unidades lexicais eleitas, para isso, observamos os vocábulos e as entradas de cada verbete. Essa compreensão nos proporcionará a apreensão da relação língua(s)-cultura(s), dadas as funções sócio-histórico-culturais da Lexicografia diacrônica. Em outras palavras, neste trabalho desenvolvemos de forma prioritária dois eixos temáticos: i) questões diacrônicas para estudo de campo semântico específico; ii) a investigação diacrônica dos brasileirismos e as modificações ocorridas, em verbetes específicos, no que compreende a(s) língua(s) e a(s) cultura(s).

Para balizar os assuntos investigados, alcançar resultados que nos levem a compreender as construções vocabulares em questão e esclarecer o modo como esta pesquisa foi articulada, delimitamos por objetivo geral a possibilidade de depreender as mudanças (ou não mudanças) lexicais, em níveis morfológico e semântico, no campo semântico da fauna e da flora brasileira, em, especificamente, cinco verbetes de um bloco de cinco dicionários de língua geral. Para tanto, definimos por objetivos específicos as competências de: a) realizar uma explanação teórica sobre as questões diacrônicas nos estudos do léxico; b) discorrer sobre as origens dos chamados brasileirismos; c) investigar os modos como essas mudanças (ou não mudanças) linguísticas estão atreladas ao contexto sociocultural do país. 
Nessa conjuntura, fizemos a delimitação de cinco vocábulos, de origem em línguas indígenas. $\mathrm{O}$ Quadro 1 a seguir demonstra o modo como cada um dos vocábulos aparece grafado nos dicionários selecionados:

Quadro 1 - Os vocábulos.

\begin{tabular}{|c|c|c|c|c|c|}
\hline \multirow[t]{2}{*}{ DICIONÁRIO } & \multicolumn{5}{|c|}{ VERBETES } \\
\hline & Aipim & Arara & Bagre & Jacaré & Jiboia \\
\hline $\begin{array}{l}\text { 1. Vocabulario } \\
\text { Portuguez e } \\
\text { Latino }\end{array}$ & $\begin{array}{l}\text { AIPYI, } \\
\text { aîpyi. }\end{array}$ & ARARA, Arará. & $\begin{array}{c}\text { BAGRE, } \\
\text { bâgre. }\end{array}$ & Ilegível & GIBOYA. \\
\hline $\begin{array}{l}\text { 2. Diccionario da } \\
\text { Lingua } \\
\text { Portugueza }\end{array}$ & $\begin{array}{l}\text { AIPÍM, } \\
\text { s. m. t. }\end{array}$ & $\begin{array}{c}\text { ARÁRA, } \\
\text { s. f. }\end{array}$ & $\begin{array}{c}\text { BÁGRE, } \\
\text { s. m. }\end{array}$ & $\begin{array}{c}\text { JACARÉ, } \\
\text { s. m. ou } \\
\text { jacaréo }\end{array}$ & $\begin{array}{l}\text { GIBÓYA, } \\
\text { s. f. }\end{array}$ \\
\hline $\begin{array}{l}\text { 3. Novo } \\
\text { Diccionário da } \\
\text { Língua } \\
\text { Portuguesa }\end{array}$ & aipim $\mathrm{m}$. & arara $f$. & bagre $\mathrm{m}$. & jacar'e $\mathrm{m}$. & jib'oia $f$. \\
\hline $\begin{array}{l}\text { 4. Dicionário } \\
\text { Contemporâneo } \\
\text { da Língua } \\
\text { Portuguesa }\end{array}$ & $\begin{array}{l}\text { (a:i.pim) } \\
\text { sm. }\end{array}$ & $\begin{array}{c}\operatorname{arara}^{1} \\
\text { sf. }\end{array}$ & $\begin{array}{c}\text { (ba.gre) } \\
\text { sm. }\end{array}$ & $\begin{array}{c}\text { (ja.ca. ré) } \\
\text { sm. }\end{array}$ & $\begin{array}{c}\text { (ji. boi.a) } \\
\text { sf. }\end{array}$ \\
\hline $\begin{array}{l}\text { 5. Dicionário } \\
\text { Priberam da } \\
\text { Língua } \\
\text { Portuguesa }\end{array}$ & $\begin{array}{l}\text { ai·pim } \\
\text { (tupi ai'pï), } \\
\text { substantivo } \\
\text { masculino }\end{array}$ & $\begin{array}{l}\text { a'ra·ra } \\
\text { substantivo } \\
\text { feminino }\end{array}$ & $\begin{array}{l}\text { ba.gre } \\
\text { substantivo } \\
\text { masculino }\end{array}$ & $\begin{array}{l}\text { ja·ca'ré } \\
\text { substantivo } \\
\text { masculino }\end{array}$ & $\begin{array}{c}\text { ji·boi·a lóil } \\
(\text { tupi yi'mboya), } \\
\text { substantivo } \\
\text { feminino }\end{array}$ \\
\hline
\end{tabular}

Fonte: 1. Raphael Bluteau (1712); 2. Antonio de Moraes e Silva (1789);

3. Cândido de Figueiredo (1911); 4. Caldas Aulete (1980); 5. Priberam (2008).

Esta pesquisa justifica-se pela necessidade de desenvolver trabalhos de caráter diacrônico que crie espaços para "recuperar o percurso constitutivo de um idioma" (KRIEGER, 2010), propiciar uma "visão mais abrangente sobre a constituição do léxico do português brasileiro" (KRIEGER, 2010) e destacar que a língua possui condições intrínsecas de mutabilidade, pois pode admitir mudanças linguísticas tanto na ordem da fala, quanto na ordem da escrita. Além disso, é importante destacar que dar notoriedade à presença das línguas indígenas na construção e naturalização dos vocábulos da língua portuguesa no Brasil cria condições de possibilidade e de visibilidade para a presença das culturas étnicas no País.

\section{Material e método}

A Lexicologia Diacrônica engloba, de forma particular, três perspectivas sobre a confluência entre língua e história. Entre as diferentes nomenclaturas adotadas podemos citar: a) "dicionários 
diacrônicos (foco na evolução, usos e desusos, de vocábulos da/na língua); b) dicionários históricos (preocupação com as modificações semânticas, significações/definições, dos verbetes); c) dicionários etimológicos (enfoque nas origens das palavras)", conforme Murakawa (2009). A presente pesquisa contemplará os três aspectos apresentados, visto que consideramos que a evolução, modificação e a origem estão interligadas no trato da língua com a cultura. Para recuperar o entorno sócio-histórico de corpora deste trabalho, descrevemos a seguir as obras selecionadas.

O Vocabulario Portuguez e Latino elaborado por Raphael Bluteau foi publicado e revisado no período de 1712 até 1721. Composto por aproximadamente 43.600 verbetes, esta obra (constituída por oito tomos) é considerada a primeira de caráter dicionarístico da língua portuguesa. Em suas páginas iniciais, o dicionário apresenta uma longa dedicatória ao Rei de Portugal, bem como diversas cartas ao/do autor, prólogo do autor e notas introdutórias. Tendo em vista que a equipe de pesquisadores do Instituto de Estudos Brasileiros (IEB) da Universidade de São Paulo (USP) realizou a digitalização da obra de Bluteau, optamos por utilizar a versão online do dicionário, já que a obra pode ser encontrada na íntegra de modo público e gratuito ${ }^{1}$.

A segunda obra elencada para a investigação é um trabalho do lexicólogo português Antonio de Moraes e Silva, intitulada Diccionario da Lingua Portugueza, tendo sido publicada no ano de 1789. O autor baseou-se no Vocabulario de Bluteau (1712) e apresenta em sua primeira publicação a seguinte nota: "Diccionario da lingua portugueza composto pelo padre D. Rafael Bluteau, reformado, e accrescentado por Antonio de Moraes e Silva” (SILVA, 1789, p. 1).

Por adotar o título Diccionario ao invés de Vocabulario como fez Raphael Bluteau, sua obra foi considerada o primeiro dicionário de língua geral, assumido tanto em Portugal quanto no Brasil para consulta da língua normalizada e legitimada. O Diccionario de Silva foi reeditado dez vezes no período de 1789-1958 e chegou a contar com doze volumes e um total de 306.949 verbetes (DICIONÁRIO E GRAMÁTICA, online, 2016). Para a análise, utilizaremos a primeira edição, que se encontra disponível online e gratuita para os consulentes. Em comparação ao Vocabulário de Bluteau, acrescenta 22.000 entradas e faz de sua obra um "espaço linguístico português, um modelo de dicionário de língua autorizado, com exclusão da informação bilíngue e da informação histórica e enciclopédica em geral" (VERDELHO, 2002, p. 27).

Das obras de Moraes avançamos, em termos cronológicos, para a obra de Cândido de Figueiredo, com primeira edição em 1911, e segunda edição datada de 1913, sob o título de Novo Diccionário da Língua Portuguesa, esta última nos servirá de base para esta pesquisa, já que se encontra disponível online para consulta e dispõe de um preâmbulo com informações sobre: razão da

${ }^{1}$ Disponível em: 〈http://dicionarios.bbm.usp.br/dicionario〉. 
obra, materiais da obra, processo da obra, ortografia, pronúncia, acentuação gráfica, etimologia e gramática. Esse dicionário possui aproximadamente 136.530 verbetes.

Outro dicionário escolhido para fazer parte do estudo de corpora foi o Dicionário Caldas Aulete, que tem primeira edição datada de 1881 com aproximadamente 200 mil verbetes. O lexicógrafo português Francisco Júlio Caldas Aulete foi o idealizador do projeto do também conhecido Dicionário contemporâneo da língua portuguesa, no entanto, em vida só conseguiu trabalhar com a letra A, nesta obra, assim, o estudioso António Lopes dos Santos Valente foi quem deu prosseguimento ao projeto.

Este dicionário também está disponível em versão online, nesta são apresentadas aproximadamente "somado a outras informações como as definições e locuções, um total de 818 mil unidades de informação (verbetes, definições e locuções)" (PORTAL DA PALAVRA, online, 2016). A versão online foi lançada em 2008 e possui "o mesmo conteúdo de verbetes, mas com acesso livre na internet, um acesso direto via navegador web” (PORTAL DA PALAVRA, online, 2016).

Os verbetes do iDicionárioAulete dividem-se em dois módulos para compreensão do consulente sobre quais palavras já estavam grafadas nas edições atualizadas no Brasil até 1980 e quais foram inseridas posteriormente. Os verbetes já existentes apresentam o registro verbete original para diferenciação dos verbetes atualizados. O módulo atualizado conta com vocábulos novos e de moderna estrutura "com exemplos e abonações, sinônimos, locuções, informações gramaticais, etimologia, contextualizações (regionalismos, usos, rubricas)" (AULETE, online, 2016).

Por fim, selecionamos o Dicionário Priberam da Língua Portuguesa que apresenta como base “o Novo Dicionário Lello da Língua Portuguesa (Porto, Lello Editores, 1996 e 1999), licenciado à Priberam em 2008, no que diz respeito à informação lexicográfica para o português” (PRIBERAM, online, 2016). Esse dicionário possui a versão online e contempla cerca de 110 mil verbetes "incluindo locuções e fraseologias, cuja nomenclatura compreende o vocabulário geral, bem como os termos mais comuns das principais áreas científicas e técnicas. $\mathrm{O}$ dicionário contém sinônimos e antônimos por acepção e permite ainda a conjugação verbal” (PRIBERAM, online, 2016).

A partir da composição destes corpora, com os cinco dicionários explicitados, prosseguimos a pesquisa com a definição temática do corpus e em seguida com o recorte do corpus. Por traçarmos a relação entre língua(s) e cultura(s), delimitamos para os verbetes pesquisados o vértice comum de campo semântico relacionado à fauna e à flora brasileira, uma vez que estas unidades lexicais estão imbricadas aos chamados brasileirismos, que muito dizem sobre as origens das constituições lexicais no Brasil.

De acordo com Krieger (2010), os brasileirismos apresentam origens nas línguas indígenas, nas línguas africanas e não só. Optamos pela investigação de unidades lexicais de origem indígena, pois 
isso também nos permitirá dar visibilidade às identidades linguísticas dos povos de etnia indígena que já habitavam o Brasil, em período anterior e posterior ao processo de colonização.

Desse modo, para investigar verbetes que, de fato, tivessem origens indígenas, consultamos o Dicionário ilustrado Tupi-Guarani online, que se constitui em um projeto de valorização das línguas indígenas e objetiva ser, além de um site para consulta acadêmica, "um elo entre as pessoas que o consultam, estejam elas no Brasil ou em qualquer lugar do mundo" (DICIONÁRIO ILUSTRADO TUPI-GUARANI, online, 2016).

\section{Verbetes de origem indígena: os brasileirismos}

Os estudos lexicográficos no Brasil têm seu início datado a partir do século $\mathrm{XX}$, isto porque, segundo Krieger (2010), somente nesse período os países colonizados conquistam uma independência política e linguística capaz de iniciar a promoção e valorização de uma identidade brasileira representada da/pela língua. Esta identidade linguística no/do Brasil confere à língua portuguesa um léxico que significava "uma expressiva variante do português europeu" (KRIEGER, 2010, p. 140), já que era constituída, também, por verbetes de outras línguas, que não a de Portugal.

É importante lembrar que, no ano de 1755, foi estabelecida pelo Marquês de Pombal a lei denominada Diretório dos Índios, tornada pública em 1757 por D. José I, rei de Portugal, que determinou a proibição do uso das línguas de tronco linguístico indígena, sob pena de tortura e, até mesmo, morte, além de dispor sobre os aldeamentos indígenas, elevando estes à condição de vilas ou aldeias, administradas por um diretor. Contudo, esta política linguística precursora no País não foi capaz de deter que variados léxicos indígenas fossem incluídos ao vocabulário da língua portuguesa falada e escrita no Brasil.

Desde a inauguração dos estudos lexicográficos no Brasil, a questão das divergências entre a língua portuguesa usada em Portugal e a propagada no Brasil é bastante polêmica. Chegou-se a ponderar a existência de duas línguas autônomas, mas esta teoria logo se desfez, visto que "a maioria dos linguistas considera que há apenas variantes de uma mesma língua, e como tal, realizações distintas” (KRIEGER, 2010, p. 142).

As diferenças mais marcantes entre as variáveis são as construções vocabulares, fato que se justifica pela dinamicidade da língua, e explica a diversidade lexical entre os países (KRIEGER, 2010). Para Biderman (2002, p. 74), “o português do Brasil constitui uma variedade do português no plano da norma e, não, do sistema, sobretudo no domínio do léxico, área em que as duas variedades do português mais se diferenciam". 
À diversidade lexical da variante da língua portuguesa no Brasil dá-se o nome de brasileirismo. Inicialmente, os vocábulos assim denominados foram marginalizados pela variante da LP em Portugal, pois os linguistas portugueses defendiam que essas utilizações maculavam a língua original. Obras como O tupi na geografia nacional (SAMPAIO, 1901), Glossário Paraense (CHERMONT, 1905), Dicionário de brasileirismos. Peculiaridades Pernambucanas (GARCIA, 1915), Vocabulário Pernambucano (COSTA, 1937) e O linguajar carioca (NASCENTES, 1922) discutiam a questão dos léxicos e usos típicos do Brasil e serviram de embasamento crítico e teórico para o desenvolvimento desse tópico no País. Os primeiros dicionários que trabalharam e trouxeram os brasileirismos para seu corpus foram o Grande e novíssimo dicionário da língua portuguesa cinco tomos (FREIRE, 1939-1944), Pequeno dicionário brasileiro da língua portuguesa (NASCENTES, 1938) e Novo dicionário da língua portuguesa (FERREIRA, 1975).

No século XX, os linguistas portugueses, ainda, consideravam que os brasileirismos eram vocábulos "intrusos e empobrecedores" da LP e a distinção deste tipo de verbete, em seus dicionários, reforçava o preconceito e o receio de modificar a "língua da pátria-mãe". No entanto, para os linguistas brasileiros o dicionário funcionava como ferramenta essencial para a solidificação da língua em sua modalidade escrita, "por essas razões, durante um século, a sociedade brasileira ansiara por um dicionário que registrasse o seu léxico e a sua norma” (BIDERMAN, 2002, p. 75).

Embora aos léxicos de origem indígena e africana tenha sido atribuído um caráter negativo $\mathrm{da} /$ na língua portuguesa para o povo português, sob a perspectiva teórica e metodológica da Lexicologia Diacrônica, é possível ponderar que tais vocábulos revelam a expansão dos saberes linguísticos e das singularidades culturais da língua portuguesa no Brasil. Biderman (2001) expõe que "o léxico de uma língua que engloba o conjunto de signos linguísticos por meio dos quais o homem não só se expressa, se comunica, mas também gera novos conhecimentos e/ou assimila saberes que outros homens criaram".

De tal modo, as línguas étnicas de origens indígenas, que colaboraram com as designações da fauna e da flora brasileiras, como se verá na análise, e africanas, que colaboraram mais em relação aos aspectos religiosos e de alimentação, agregaram à língua portuguesa signos linguísticos que contemplaram em resumo a biodiversidade e, principalmente, a diversidade cultural e o recorte que cada etnia fez sobre o mundo e sobre seu país de origem e/ou de imigração.

\section{Análise e discussão}

Foi necessária a organização de quadros para melhor visualização dos verbetes elencados para o movimento de análise. Em cada um dos quadros estão dispostos os verbetes encontrados nos 
dicionários que compuseram os corpora da pesquisa, assim, foram distribuídas as entradas para cada verbete específico ${ }^{2}$.

\section{Aspectos morfológicos e semânticos: as (não) mudanças linguísticas e definicionais dos brasileirismos}

Quadro 2 - Vocabulario portuguez e latino.

\begin{tabular}{|c|c|c|c|c|c|}
\hline & AIPYI, aîpyi. & ARARA, Arará. & BAGRE, bâgre. & JACARÉ & GIBOYA. \\
\hline \multirow[t]{2}{*}{ 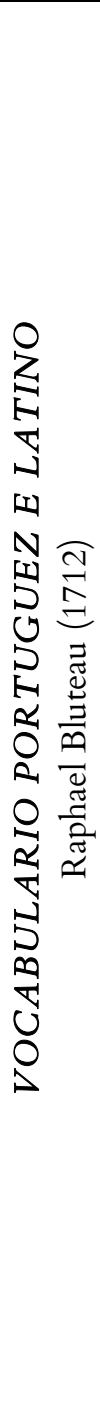 } & $\begin{array}{l}\text { Erva do Brazil, de cujas } \\
\text { raizes fazem os Indios } \\
\text { Pão, \& Vinho. Ha } \\
\text { deftaervamuitasefpecies. } \\
\text { Aipyiquacú, } \\
\text { Aipyijarandè. O a que } \\
\text { chamãoAipyiMachaxera } \\
\text { He o melhor, mais } \\
\text { faudavel, \& mais } \\
\text { goftofo. Vid. Vafconcel. } \\
\text { Noticias do Brafil, pag. } \\
246 .\end{array}$ & $\begin{array}{l}\text { He humaefpecie de } \\
\text { Papagayo grande, } \\
\text { que Fe cria no fertão } \\
\text { do Brafifl. He } \\
\text { vermelho, femeado } \\
\text { de algumas } \\
\text { pennasamarellas, \& } \\
\text { tem as azas azuis, } \\
\text { \&hum rabo muyto } \\
\text { comprido, \&fermofo. }\end{array}$ & $\begin{array}{l}\text { Peixe comprido, } \\
\text { \&rabiforcado; } \\
\text { tem a pelle de } \\
\text { cor de prata; He } \\
\text { bom de comer; } \\
\text { as feridas que } \\
\text { faz } \\
\text { faõdifficultozas } \\
\text { de curar, } \\
\text { \&caufão grade } \\
\text { dor. Hâ muitas } \\
\text { efpeciesdelle, } \\
\text { como Fe pode } \\
\text { ver em Jorge } \\
\text { Mafgravo, lib. } 4 . \\
\text { cap. } 16 . \text { A } \\
\text { invenção defta } \\
\text { peçonha, He } \\
\text { dos moradores } \\
\text { da Ilha } \\
\text { C;amatra, a qual } \\
\text { Fe coompoem } \\
\text { com a efpinha } \\
\text { do peixe, a que } \\
\text { nefte Reino } \\
\text { chamamos } \\
\text { bagre. Barros, } 2 . \\
\text { Dec. fol. } 142 . \\
\text { col.4. }\end{array}$ & $\begin{array}{l}\text { (ilegível } \\
\text { no } \\
\text { dicionário) }\end{array}$ & $\begin{array}{l}\text { Cobra do } \\
\text { Brafil de } \\
\text { moftruofa } \\
\text { grandeza. } \\
\text { Vid. } \\
\text { Cobra de } \\
\text { veado. }\end{array}$ \\
\hline & \multicolumn{5}{|c|}{ DEFINIÇÃO } \\
\hline
\end{tabular}

Fonte: Bluteau (1712).

\footnotetext{
${ }^{2}$ É válido ressaltar que tanto os vocábulos, quanto as entradas foram redigidas, nos quadros, exatamente como estavam nas obras dicionarísticas, para preservar a originalidade dos verbetes.
} 
Quadro 3 - Diccionario da lingua portugueza.

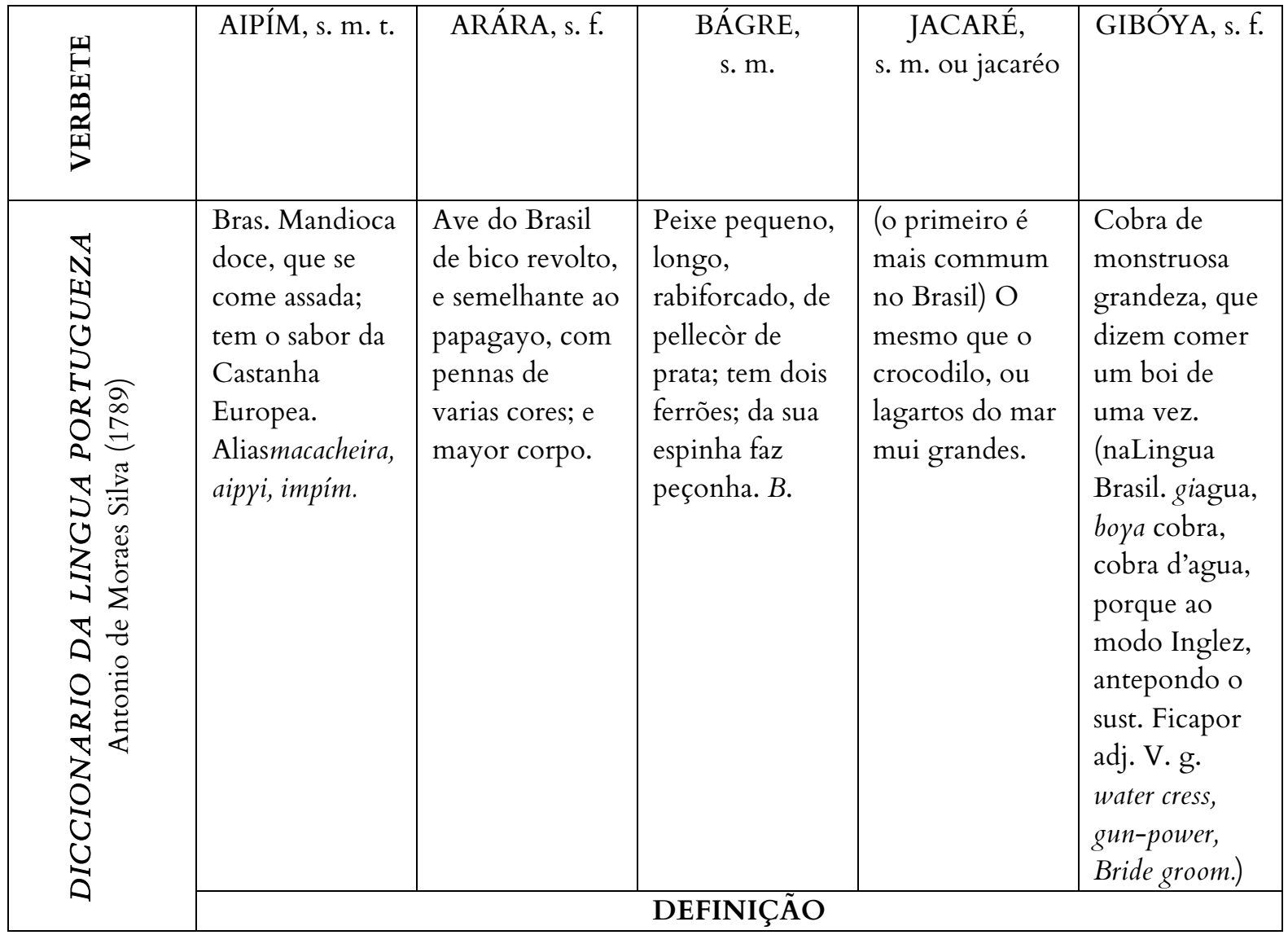

Fonte: Silva (1789).

Quadro 4 - Novo diccionário da língua portuguesa.

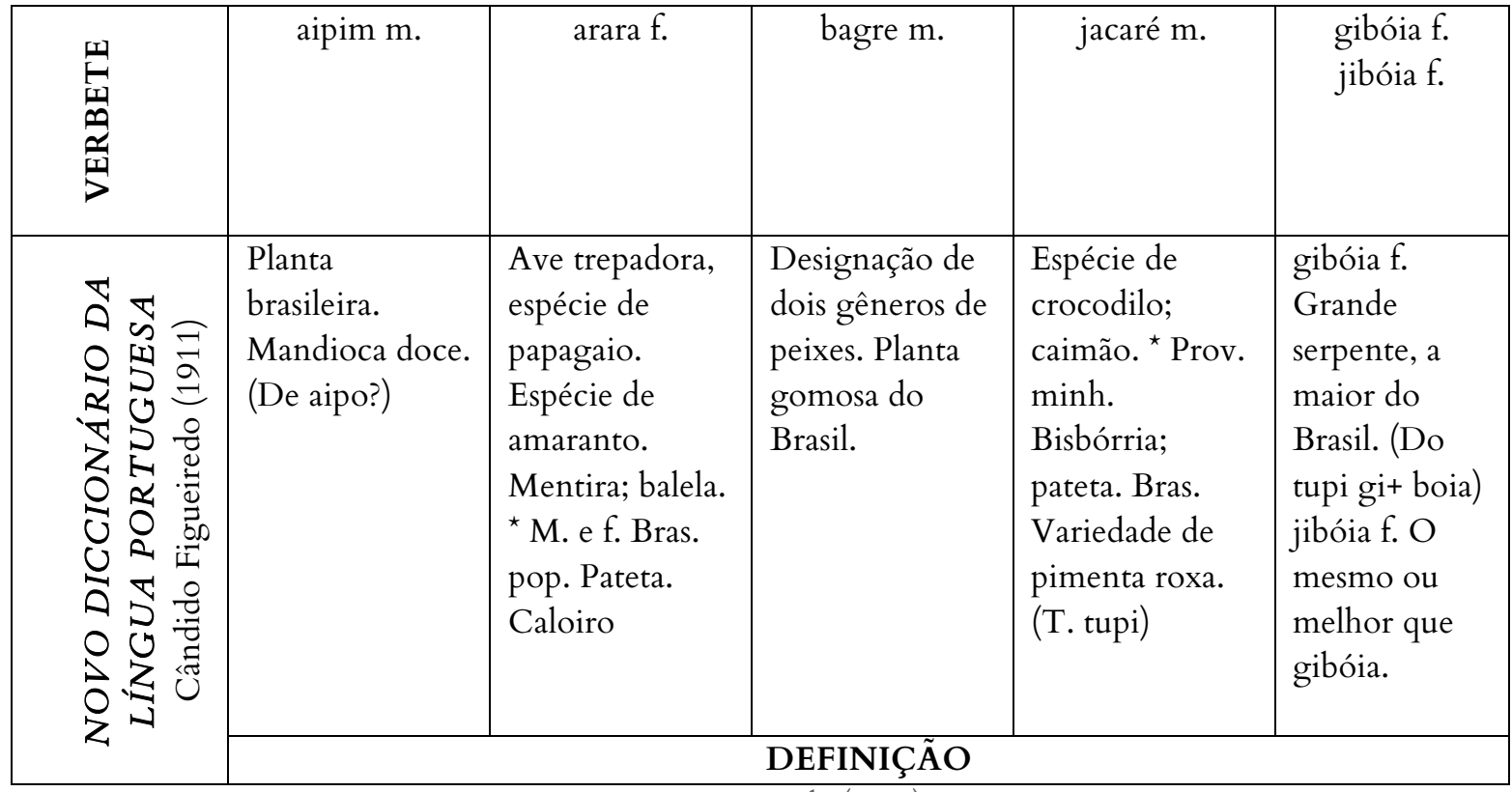

Fonte: Figueiredo (1911). 
Quadro 5 - Dicionário Caldas Aulete.

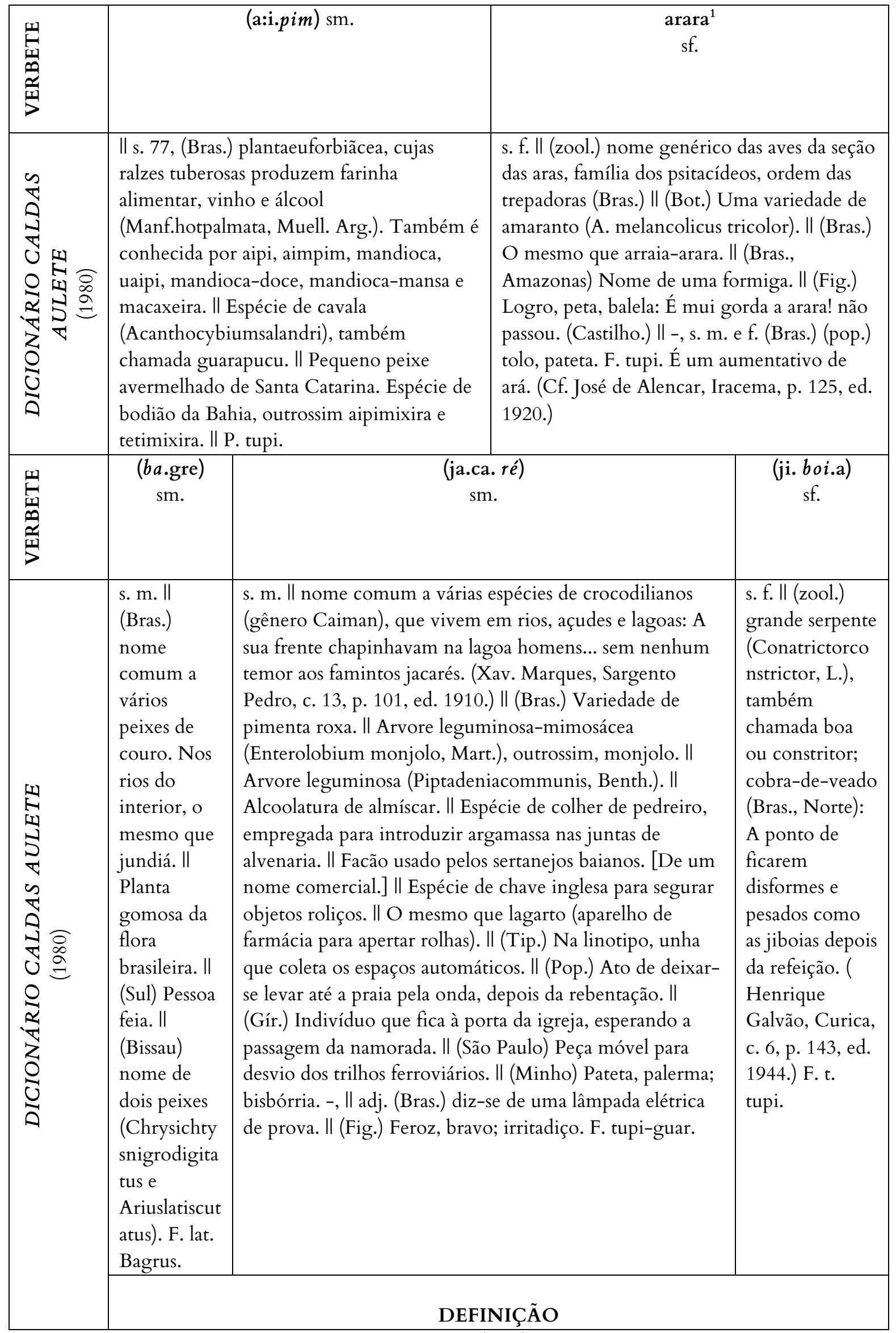

Fonte: Aulete (1980). 
Quadro 6 - Dicionário Priberam da Língua Portuguesa.

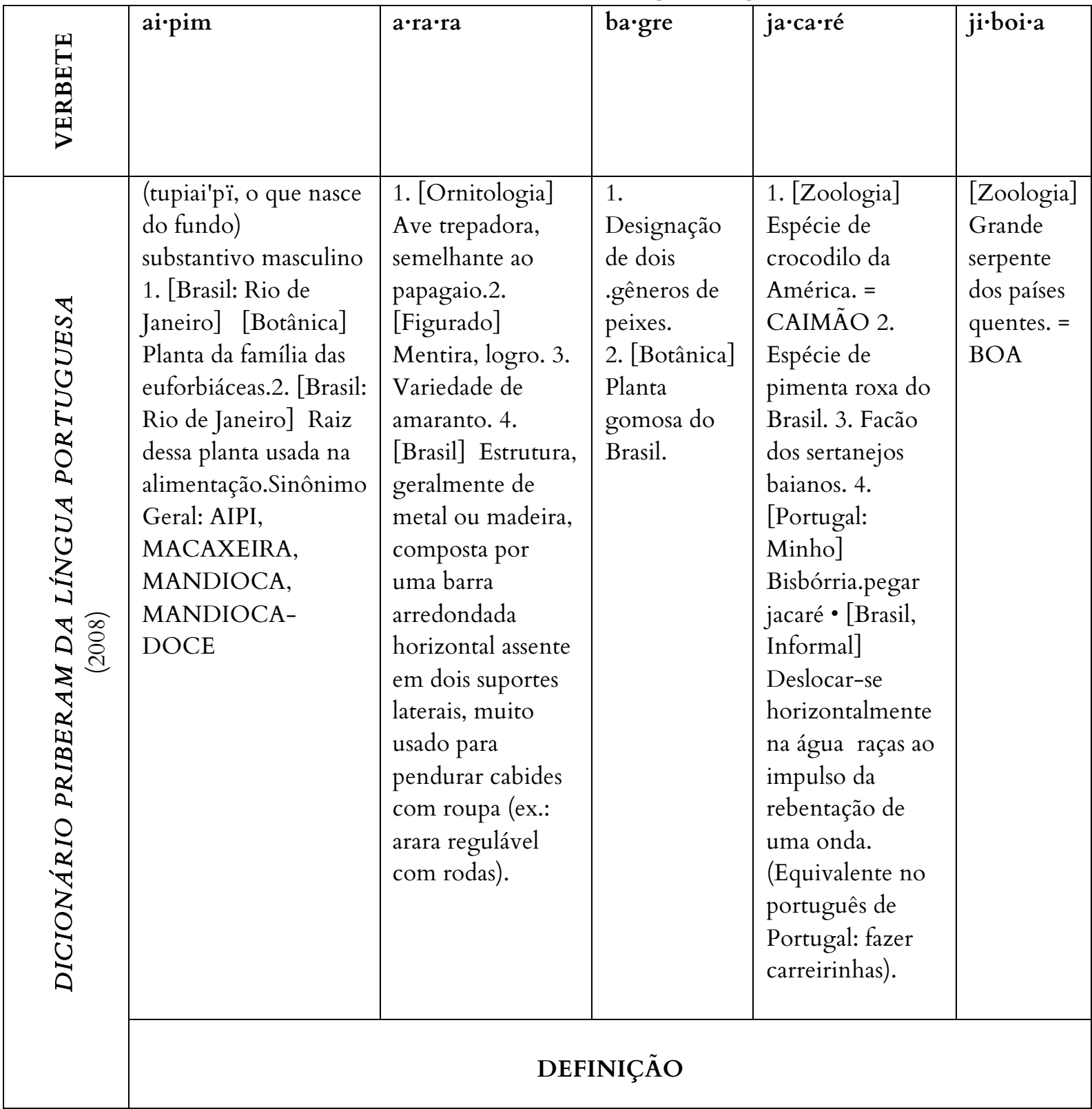

Fonte: Priberam (2008).

Segundo Neves (2012), com base na Nomenclatura Gramatical Brasileira (NGB), a morfologia pode ser segmentada em três seções: “a) estrutura e formação de palavras; b) flexões; c) classificação de palavras" (NEVES, 2012, p. 217). A morfologia dos vocábulos trata das "formas das palavras em diferentes usos e construções" (MATTHEWS, 1974, p. 156 apud LAROCA, 1994, p. 13). Os estudos morfológicos objetivam análises que investiguem a estrutura interna das palavras, desde as unidades mínimas aos demais constituintes de um vocábulo. 
$\mathrm{Na}$ primeira $^{3}$ seção, investigam-se informações acerca de aspectos: fonológicos (fonema e sílaba); morfológicos (morfema); semânticos (significado); sintáticos (função e ligação) ${ }^{4}$.

Nas cinco obras pesquisadas, as variações encontradas concentram-se no nível fonológico e apresentam-se marcadas pela inserção gráfica de acentuação aguda das sílabas tônicas, para indicação de pronúncia de vogal aberta, como em: Aipím; Arára; Bágre; Jacaré; Gibóyia (SILVA, 1789). Os demais dicionários não apresentam marcação de acento agudo nas três primeiras unidades lexicais (ULs) mencionadas, quanto à penúltima unidade lexical (UL) todos os dicionários mantêm o acento e o último apresenta acentuação em dois dicionários (SILVA, 1789; FIGUEIREDO, 1911).

A UL jacaré mantém acentuação por tratar-se de uma oxítona, pois seguem acentuando-se as palavras oxítonas terminadas em -a, -e, -o (seguidas ou não pela desinência de plural -s), -em e -es. A UL aipím, embora se constitua em uma palavra oxítona, perde a acentuação, uma vez que com o passar do tempo as oxítonas terminadas em -az, -ez, -iz, -oz, -uz, -i(s), -u(s), -or, -im deixam de apresentar o acento agudo. A UL gibóyia perdeu a acentuação aguda, recentemente, com o novo acordo ortográfico (2009), pois as palavras paroxítonas com ditongação aberta em -ei e/ou -oi deixaram de ser acentuadas.

As variações diacrônicas encontradas, na ordem dos aspectos fonológicos, entre os cinco dicionários também aparecem no nível da marcação dos fonemas em trocas de [g] por [j], pelo fato de ambas as marcações representarem o fonema / $3 /$. E, ainda, nas trocas de [y] por [i], por ambos representarem o fonema/i/. $\mathrm{O}[\mathrm{y}]$ é uma letra bastante utilizada em palavras indígenas, como exemplo, citamos algumas palavras da família linguística do Tupi-Guarani: "Ayty: ninho (parati); Kamby: leite, líquido do seio; Yapira: mel” (DICIONÁRIO INDÍGENA, online, 2016).

Tais modificações demonstram a atualização/evolução fonológica dos vocábulos, de acordo com as novas normas ortográficas ${ }^{5}$ que surgiram no decorrer do tempo, mas não apresentam mudanças morfológicas significativas. Essas mudanças, no nível da estrutura mórfica, poderiam ser proporcionadas pelo uso frequente, nos níveis da fala e da escrita, da UL pela sociedade, como no caso de palavras da língua portuguesa, que se originaram na língua latina. Um exemplo bastante conhecido que podemos citar é o da evolução do pronome de tratamento Vossa Mercê, que passa pelas formas Vossemecê>Vosmecề Voscê>Você>ocê (oralidade)>cê (oralidade).

\footnotetext{
${ }^{3}$ As demais seções (flexões e classificação de palavras) serão contempladas, concomitantemente, com a seção de estrutura e formação de palavras.

${ }^{4}$ Neste trabalho não investigaremos os aspectos sintáticos dos vocábulos, pois não utilizaremos contextos reais de produção para averiguar o modo como funcionam, sintaticamente, tais palavras.

${ }^{5}$ As reformas ortográficas referem-se à língua portuguesa escrita e buscam viabilizar a difusão internacional da língua, de modo que a unificação pretendida pelos acordos ortográficos diminui problemas na execução de testes de proficiência linguística e na publicação de livros (SILVA, 2009).
} 
Quadro 7 - Processo de evolução morfossintática e fonológica do vocábulo você.

\begin{tabular}{|c|c|c|c|c|}
\hline $\begin{array}{l}\text { Pronome de } \\
\text { tratamento }\end{array}$ & Vossa Mercê & Vossemecê & $\begin{array}{c}\text { Vosmecê } \\
\text { Voscê }\end{array}$ & Você/ Ocê/ Cê \\
\hline 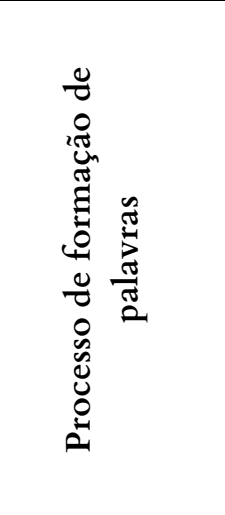 & $\begin{array}{l}\text { Composição vocabular } \\
\text { por simples justaposição } \\
\text { de bases livres: } \\
\text { Vossa (Palavra 1) + Mercê } \\
\text { (Palavra 2) = Vossa Mercê } \\
\text { (Palavra 3). } \\
\text { Vossa (sílaba tônica } V o) . \\
\text { Mercê (sílaba tônica cê). }\end{array}$ & $\begin{array}{l}\text { Composição } \\
\text { vocabular por } \\
\text { aglutinação de } \\
\text { bases. } \\
\text { Voss (Base 1); e } \\
\text { (acréscimo); mecê } \\
\text { (Base 2). } \\
\text { Vossemecê (vogal } \\
\text { de ligação) } \\
\text { Vossemecê (sílaba } \\
\text { tônica cê). }\end{array}$ & $\begin{array}{l}\text { Composição } \\
\text { por } \\
\text { truncamento, } \\
\text { junção com } \\
\text { fragmentos de } \\
\text { bases. } \\
\text { Vos + mecê/cê. } \\
\text { Vosmecê, } \\
\text { Voscê (sílaba } \\
\text { tônica cề). }\end{array}$ & $\begin{array}{l}\text { Redução vocabular } \\
\text { por derivação } \\
\text { regressiva. } \\
\text { Você, ocê, cê (sílaba } \\
\left.\text { tônica } c \hat{e}^{\star \star}\right) \text {. }\end{array}$ \\
\hline Informações & \multicolumn{4}{|c|}{$\begin{array}{l}\text { * No processo de formação de palavras “a composição vocabular implica a junção de } \\
\text { duas ou mais palavras, com ou sem redução de estrutura mórfica das bases: palavra } 1+ \\
\text { palavra } 2 \text { = palavra 3" (LAROCA, 1994, p. } 76 \text { ) } \\
{ }^{\star \star} \text { Vocábulo reduzido à sílaba tônica, que se manteve igual após a segunda modificação } \\
\text { na composição vocabular. }\end{array}$} \\
\hline
\end{tabular}

Ao investigarmos a estrutura e formação de palavra entre os vocábulos mencionados, é notável a complexidade dos processos fonológicos e morfossintáticos pelos quais o vocábulo "você" percorre, em contraste à simplicidade (e não alteração) morfológica no movimento diacrônico de palavras como: Aipyi>Aipím>Aipim, e Giboyia>Gibóyia>Gibóia>Jibóia>Jiboia.

Quanto aos aspectos morfológicos, importa destacar que, para Zanotto (1986), o "morfema é a unidade mórfica mínima de que se compõe o vocábulo. No âmbito da morfologia é indivisível em unidades menores. É obrigatoriamente portadora de alguma significação ou função gramatical” (ZANOTTO, 1986, p. 29).

Os morfemas "dividem-se em lexicais e gramaticais. Essa divisão leva em conta a função ou significação que o morfema desempenha no conjunto do vocábulo” (ZANOTTO, 1986, p. 29). Os morfemas lexicais são também conhecidos por lexemas ou semantemas e são encontrados na raiz do vocábulo, já os gramaticais contém informações sobre as funções gramaticais do vocábulo (ZANOTTO, 1986).

Deste modo, o vocábulo mórfico pode ser constituído, basicamente, por três elementos: a) Radical (R): responsável pela apresentação da significação básica do vocábulo; b) Vogal temática (VT): é um segmento fônico que se acrescenta ao radical (primário ou não) para agrupar vocábulos (nomes e verbos) em categorias; c) Afixos derivacionais: prefixos (MD), infixos (MD) e sufixos (MD) flexionais: flexão de tempo (DMT), modo (DMT), número e pessoa (DNP) - [verbos], e gênero 
(DG) e número (DN) - [nomes]. Os afixos derivacionais são responsáveis pela derivação de novas palavras e os flexionais pela capacidade de flexionar as palavras (ZANOTTO, 1986).

Quadro 8-Vocábulos nominais: análise morfológica I.

\begin{tabular}{|c|c|c|c|c|}
\hline $\begin{array}{c}\text { VOCÁBULOS } \\
\text { NOMINAIS }\end{array}$ & $\mathbf{R}$ & VT & TEMA & A/TEMÁTICO \\
\hline AIPIM & AIPIM & $\varnothing$ & - & Atemático \\
\hline ARARA & ARAR- & A & ARARA & Temático \\
\hline BAGRE & BAGR- & E & BAGRE & Temático \\
\hline JACARÉ & JACARÉ & $\varnothing$ & - & Atemático \\
\hline JIBOIA & JIBOI & A & JIBOIA & Temático \\
\hline
\end{tabular}

Fonte: Análise morfológica de autoria própria em relação

aos apontamentos teóricos de Zanotto (1986).

Na maioria das vezes, os vocábulos nominais e verbais não são destacados nos dicionários formais de língua geral em suas formas derivacionais, portanto, no Quadro 9, utilizaremos vocábulos derivados dos cinco verbetes, a título de exemplificação, para que seja possível compreender o modo como poderiam ser vislumbrados os demais aspectos morfológicos em relação a esses vocábulos. E no Quadro 10, subsequente, serão apresentados os aspectos semânticos das entradas dos verbetes nos cinco dicionários, com o intuito de salientar as mudanças de significados que tais entradas manifestaram.

Quadro 9 - Vocábulos nominais e vocábulo verbal: análise morfológica II.

\begin{tabular}{|c|c|c|c|c|c|}
\hline VOCÁBULO & $\begin{array}{c}\text { MD } \\
\text { (prefixos, } \\
\text { sufixos) }\end{array}$ & $\begin{array}{c}\text { Rz } \\
\text { (Semantem } \\
\text { a) }\end{array}$ & $\begin{array}{c}\text { MD } \\
\text { (prefixos, } \\
\text { sufixos) }\end{array}$ & $\begin{array}{c}\text { VT } \\
\text { (vogal temática } \\
\text { nominal e verbal) }\end{array}$ & $\begin{array}{c}\text { MF } \\
\text { (desinências) }\end{array}$ \\
\hline AIPINS & - & Aipi- & - & - & n-s \\
\hline ARARINHAS & - & Arar- & $-i n h-$ & a & o \\
\hline BAGRINHO & - & Bagr- & $-i n h-$ & - & $\mathrm{s}$ \\
\hline JACARÉS & - & Jacaré & - & a & r (DMT) \\
\hline JIBOIAR & - & Jiboi- & - & & \\
\hline
\end{tabular}

Fonte: DICIONÁRIO INFORMAL, online, 2016. 
Quadro 10 - Análise semântica das definições dos verbetes.

\begin{tabular}{|c|c|c|c|c|c|}
\hline & $\begin{array}{l}\text { BLUTEAU } \\
(1712)\end{array}$ & $\begin{array}{l}\text { SILVA } \\
(1789)\end{array}$ & $\begin{array}{l}\text { FIGUEIREDO } \\
\text { (1911) }\end{array}$ & $\begin{array}{l}\text { AULETE } \\
(1980)\end{array}$ & $\begin{array}{c}\text { PRIBERAM } \\
(2008)\end{array}$ \\
\hline 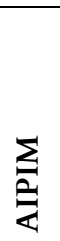 & $\begin{array}{l}\text { Significado } \\
\text { único: } 1 . \\
\text { Descrição da } \\
\text { raiz. }\end{array}$ & $\begin{array}{l}\text { Significado } \\
\text { único: } 1 . \\
\text { Descrição da } \\
\text { raiz. }\end{array}$ & $\begin{array}{l}\text { Significado único: } 1 . \\
\text { Apresentação da } \\
\text { raiz. }\end{array}$ & $\begin{array}{l}\text { Dois significados: } \\
\text { 1. Descrição da raiz; } 2 . \\
\text { descrição de espécie de } \\
\text { peixe. }\end{array}$ & $\begin{array}{l}\text { Significado único: } 1 . \\
\text { Descrição da raiz. }\end{array}$ \\
\hline$\underset{\nwarrow}{\nwarrow}$ & $\begin{array}{l}\text { Significado } \\
\text { único: } 1 . \\
\text { Descrição de } \\
\text { espécie de } \\
\text { ave. }\end{array}$ & $\begin{array}{l}\text { Significado } \\
\text { único: } 1 . \\
\text { Descrição de } \\
\text { espécie de } \\
\text { ave. }\end{array}$ & $\begin{array}{l}\text { Quatro significados: } \\
\text { 1. Apresentação de } \\
\text { espécie de ave; } 2 . \\
\text { Apresentação de } \\
\text { espécie de flor; } 3 \text {. e } \\
\text { 4. Apresentação de } \\
\text { sentidos figurado. }\end{array}$ & $\begin{array}{l}\text { Cinco significados: } 1 . \\
\text { Apresentação de espécie de } \\
\text { ave; } 2 . \text { Apresentação de } \\
\text { espécie de flor; } 3 \text {. } \\
\text { Apresentação de espécie de } \\
\text { inseto; } 4 \text {. Apresentação de } \\
\text { sentido figurado; } 5 \text {. } \\
\text { Apresentação de vocábulo } \\
\text { aumentativo para "ará". }\end{array}$ & $\begin{array}{l}\text { Quatro significados: } \\
\text { 1. Apresentação de } \\
\text { espécie de ave; } 2 . \\
\text { Apresentação de } \\
\text { sentido figurado; } \\
\text { 3. Apresentação de } \\
\text { espécie de flor; } 4 . \\
\text { Descrição de objeto. }\end{array}$ \\
\hline 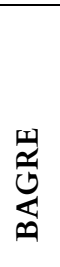 & $\begin{array}{l}\text { Significado } \\
\text { único: } 1 . \\
\text { Descrição de } \\
\text { espécie de } \\
\text { peixe }\end{array}$ & $\begin{array}{l}\text { Significado } \\
\text { único: } 1 . \\
\text { Descrição de } \\
\text { espécie de } \\
\text { peixe. }\end{array}$ & $\begin{array}{l}\text { Dois Significados: } 1 . \\
\text { Apresentação de } \\
\text { espécie de peixe; } 2 . \\
\text { Apresentação de } \\
\text { espécie de planta. }\end{array}$ & $\begin{array}{l}\text { Três significados: } 1 . \\
\text { Apresentação de espécie de } \\
\text { peixe; } 2 . \text { Apresentação de } \\
\text { espécie de planta; } 3 \text {. } \\
\text { Apresentação de } \\
\text { xingamento. }\end{array}$ & $\begin{array}{l}\text { Dois significados: } 1 . \\
\text { Apresentação de } \\
\text { espécie de peixe; } 2 \text {. } \\
\text { Apresentação de } \\
\text { espécie de planta. }\end{array}$ \\
\hline 崖 & $\varnothing$ & $\begin{array}{l}\text { Significado } \\
\text { único: } \\
\text { Apresentação } \\
\text { de espécie de } \\
\text { animal. }\end{array}$ & $\begin{array}{l}\text { Três significados: } 1 . \\
\text { Apresentação de } \\
\text { espécie de animal; } 2 . \\
\text { Apresentação de } \\
\text { sentido figurado. } 3 \text {. } \\
\text { Apresentação de } \\
\text { espécie de pimenta; }\end{array}$ & $\begin{array}{l}\text { Treze significados: } 1 . \\
\text { Apresentação de espécie de } \\
\text { animal; } 2 \text {. Apresentação de } \\
\text { espécie de pimenta; } 4.5 .6 . \\
\text { 7. 10. } 12 . \text { Apresentação de } \\
\text { espécie de objetos; } 8 . \\
\text { Descrição de nova } \\
\text { construção vocabular; } 9 . \\
\text { Apresentação de gíria; } 11 . \\
\text { Apresentação de } \\
\text { xingamento; } 13 . \\
\text { Apresentação de adjetivo. }\end{array}$ & $\begin{array}{l}\text { Quatro significados: } \\
\text { 1. Apresentação de } \\
\text { espécie de animal; } 2 . \\
\text { Apresentação de } \\
\text { espécie de pimenta; } \\
\text { 3. Apresentação de } \\
\text { espécie de objeto; } 4 . \\
\text { Descrição de nova } \\
\text { construção } \\
\text { vocabular. }\end{array}$ \\
\hline$\underset{\Xi}{\Xi}$ & $\begin{array}{l}\text { Significado } \\
\text { único: } 1 . \\
\text { Apresentação } \\
\text { de espécie de } \\
\text { serpente. }\end{array}$ & $\begin{array}{l}\text { Significado } \\
\text { único: } 1 . \\
\text { Descrição de } \\
\text { espécie de } \\
\text { serpente. }\end{array}$ & $\begin{array}{l}\text { Significado único: } 1 . \\
\text { Apresentação de } \\
\text { espécie de serpente. }\end{array}$ & $\begin{array}{l}\text { Dois significados: } 1 . \\
\text { Apresentação de espécie de } \\
\text { serpente; } 2 \text {. Apresentação } \\
\text { de sentido figurado. }\end{array}$ & $\begin{array}{l}\text { Significado único: } 1 . \\
\text { Apresentação de } \\
\text { espécie de serpente. }\end{array}$ \\
\hline
\end{tabular}

Fonte: Bluteau (1712); Silva (1789); Figueiredo (1911); Aulete (1980); Priberam (2008). 
Ainda que tenhamos mostrado uma breve análise morfológica sobre as ULs aipins, ararinhas, bagrinho, jacarés, jiboiar (Quadro 9), nosso enfoque foi demonstrar, diacronicamente, as modificações que ocorreram nos aspectos morfológicos nos verbetes aipim, arara, bagre, jacaré, jiboia (assim redigidos atualmente) e semânticos (no nível da significação) nas entradas de cada um desses verbetes.

Quanto às mudanças na estrutura e formação de palavras, já é sabido que se devem considerar os elementos fonológicos, morfológicos, semânticos e sintáticos, nesse sentido, compreendemos que os brasileirismos investigados apresentam modificações estruturais, prioritariamente, no nível fonológico das ULs. Apesar dessas ULs terem origens indígenas, possível e aproximadamente, de cinco séculos de existência e terem sido legitimamente incluídas à língua portuguesa eles não passaram por mudanças expressivas, tanto em relação aos aspectos morfológicos, quanto em relação aos fonológicos, se comparados a vocábulos como Vossa Mercê>cê, como exemplificamos anteriormente.

Sobre os aspectos semânticos foi necessário considerarmos as entradas incluídas para cada vocábulo em cada uma das obras. É possível observar que com o decorrer do tempo os dicionários acrescentam novas significações aos verbetes, dados os outros sentidos que emergem nos variados contextos sociais. Embora a estrutura das ULs não tenha sofrido transformações significativas, os sentidos atribuídos a elas foram ampliados, como também surgiram novos vocábulos e expressões para contemplar, especificamente, tais significações, como no caso de:

(1) Ficar uma arara: tal expressão adquire novo significado e pode apresentar relação direta com as significações apresentadas pelos dicionários Figueiredo, Aulete e Priberam - [mentira, balela, logro, peta, mui gorda]. A expressão Ficar uma arara pode ter emergido como uma atitude característica daquele que recebia as ofensas informadas pelos dicionários;

(2) Cabeça de bagre: esta expressão circula sentidos de 'qualidade aquém da esperada'; no dicionário Aulete a significação referencial para esse novo sentido, que vai além da descrição da espécie de peixe, é pessoa feia;

(3) Pegar jacaré: esta expressão se constitui como uma nova construção vocabular, assim como as anteriores, e pode ser visualizada nos dicionários Aulete e Priberam com as descrições "ato de deixar se levar até a praia pela onda depois da rebentação" e "deslocar-se horizontalmente na água graças ao impulso da rebentação de uma onda", respectivamente;

(4) Jiboiar: verbo criado a partir da descrição da ação da jiboia após se alimentar. A significação nova já é demonstrada no dicionário Aulete com a seguinte definição "a ponto de ficarem disformes e pesados como as jibóias depois da refeição". 
Desses novos significados, apenas ficar uma arara não aparece referenciada em nenhum dos dicionários, nem mesmo nos mais recentes (Aulete e Priberam), já as expressões Cabeça de bagre e Jiboiar são caracterizadas como novos verbetes (nos dois dicionários mencionados), enquanto pegar jacaré é apresentado somente como um novo significado para a entrada jacaré (em Priberam).

Para as poucas alterações sofridas pelas ULs analisadas conjecturamos três hipóteses: (a) elas são pouco utilizadas pela sociedade; (b) não são/foram realizadas discussões de caráter linguístico sobre a estrutura e formação das ULs de origens indígenas; (c) elas permanecem com poucas alterações para preservação dos traços das línguas indígenas na língua portuguesa.

A hipótese (a) não pôde ser confirmada, visto que a partir de breves pesquisas no site de busca na internet obtivemos inúmeros resultados que exploravam as ULs investigadas, com textos de caráter instrucional, informativo e expositivo, em especial. A hipótese (b) igualmente não pôde ser constatada, já que as respostas no site de busca na internet demonstraram que há variadas investigações científicas, de caráter linguístico, sendo realizadas no Brasil sobre as línguas indígenas, como exemplos podemos citar alguns trabalhos que foram encontrados:

\begin{tabular}{|l|l|l|l|}
\hline \multicolumn{1}{|c|}{ Quadro 11 - Pesquisas científicas sobre línguas indígenas. } \\
\hline $\begin{array}{l}\text { Comparação de aspectos da } \\
\text { gramática em línguas indígenas } \\
\text { brasileiras }\end{array}$ & Marcus Maia & CARÁTER & ANO \\
\hline $\begin{array}{l}\text { Interface morfologia e sintaxe em } \\
\text { Tenetéfico }\end{array}$ & Ricardo Campos de Castro & $\begin{array}{l}\text { Dissertação } \\
\text { (Mestrado) }\end{array}$ & 2007 \\
\hline $\begin{array}{l}\text { Sobre a morfologia e a sintaxe da } \\
\text { língua Guajá (FamíliaTupí- } \\
\text { Guaraní) }\end{array}$ & Marina Maria Silva Magalhães & $\begin{array}{l}\text { Tese } \\
\text { (Doutorado) }\end{array}$ & 2007 \\
\hline $\begin{array}{l}\text { Estudo morfológico e sintático da } \\
\text { língua mundurukú (tupí) }\end{array}$ & Dioney Moreira Gomes & $\begin{array}{l}\text { Tese } \\
\text { (Doutorado) }\end{array}$ & 2006 \\
\hline $\begin{array}{l}\text { Línguas brasileiras: para o } \\
\text { conhecimento das línguas } \\
\text { indígenas }\end{array}$ & Aryon Dall'Igna Rodrigues & Livro & 1994 \\
\hline $\begin{array}{l}\text { Gramática do kamaiurá: língua } \\
\text { tupi-guarani do alto Xingu }\end{array}$ & Lucy Seki & Livro & 2000 \\
\hline
\end{tabular}

Fonte: Site de busca na internet Google.

Assim, após refletirmos e investigarmos a temática abordada nesta pesquisa e descartamos as duas primeiras hipóteses lançadas, a última nos parece bastante possível, uma vez que mesmo incluídas à língua portuguesa, tais unidades originam-se a partir de línguas indígenas e, portanto, apresentam sinais de preservação quanto à estrutura e formação de palavras.

Silva Neto (1976, p. 50) esclarece que a língua geral (famílias linguísticas do Tupi-Guarani) do Brasil, no período de colonização, apresentava material morfológico reduzido, se comparada à língua 
portuguesa na variedade de Portugal, pois não apresentava declinação e nem conjugação. Deste modo, é possível atribuir às poucas modificações que ocorreram nos verbetes analisados a um contexto social e linguístico de preservação dos traços morfológicos das línguas indígenas na língua portuguesa.

\section{Considerações finais}

Buscamos, neste trabalho, compreender as mudanças linguísticas que ocorreram em verbetes de campo semântico relacionado à fauna e à flora do/no Brasil. Para isso, a explanação teórica sobre os estudos diacrônicos, no campo da Lexicologia, foi imprescindível, visto que nos forneceu embasamento teórico para a investigação do corpus selecionado.

A seção sobre materiais e metodologias empregadas para a análise visou elucidar o desenvolvimento de dicionários de língua geral (portuguesa) e, a partir desse levantamento cronológico, foi possível contemplar, diacronicamente, os processos de evolução das obras em questão. Na seção em que discutimos a questão dos brasileirismos, houve a possibilidade de esclarecer os porquês da necessidade de fazer essa distinção para unidades lexicais que foram inseridas à língua portuguesa e possuíam origens em línguas indígenas e africanas, em especial.

Os movimentos analíticos realizados evidenciaram que os vocábulos de origens em línguas indígenas não apresentaram modificações significativas em suas estruturas morfológicas, mas a eles foram atribuídos significados divergentes com o decorrer do tempo, o que destaca tanto a utilização dos vocábulos nos mais variados contextos sociais, quanto os acréscimos semânticos inseridos nos verbetes das obras investigadas.

Ponderamos que essas inalterações devem-se à preservação da estrutura e formação de palavras das línguas étnicas na língua portuguesa. Tal preservação cria possibilidades de valorização cultural e linguística das etnias indígenas e ressalta a forma como a língua legitimada e oficializada no País mantém relações estreitas com outras línguas e culturas, ainda que a marcação e demonstração dessas origens só sejam percebidas por ULs com a expressão "Bras." utilizada nos dicionários para menção aos brasileirismos. 


\section{Referências bibliográficas}

AUleTE, F. J. de C. Dicionário Contemporâneo da Língua Portuguesa (7 ed.). Rio de Janeiro: Delta, 1980. Disponível em: <http://www.aulete.com.br/>. Acesso em: 13 nov. 2016.

BALDINI, L. J. S. A nomenclatura gramatical brasileira interpretada, definida, comentada e exemplificada. Dissertação (Mestrado em Linguística). Faculdade de Letras, Universidade Estadual de Campinas. Campinas, 1999.

BIBLIOTECA BRASILIANA GUITA E JOSÉ MINDLIN. [S.l.: s.n.]. Disponível em: $<$ http://dicionarios.bbm.usp.br/dicionario $>$. Acesso em: 13 nov. 2016.

BIDERMAN, M. T. C. A formação e a consolidação da norma lexical e lexicográfica no português do Brasil. In: NUNES, J. H.; PETTER, M. M. T. História do saber lexical e constituição de um léxico brasileiro. São Paulo: Humanitas; Campinas: Pontes Editores, 2002.

BIDERMAN, M. T. C. Dicionário e léxico do português brasileiro. São Paulo: Editora Martins Fontes, 2001.

BLUTEAU, R. Vocabulario Portuguez e Latino. Lisboa, LX: Officina de Pascoal da Sylva, 1712. Disponível em: <http://dicionarios.bbm.usp.br/pt-br/dicionario/edicao/1 >. Acesso em: 13 nov. 2016.

CASTRO, R. C. de. Interface morfologia e sintaxe em Tenetehára. Dissertação (Mestrado em Linguística). Universidade Federal de Minas Gerais (UFMG). Belo Horizonte, 2007. Disponível em: <https://repositorio.ufmg.br/handle/1843/ALDR-797JYN>. Acesso em 28 jan. 2017.

COSTA, F. A. P. da. Vocabulário pernambucano. Revista do instituto arqueológico, histórico e geográfico pernambucano, p. 159-162, 1937.

DICIONÁRIO E GRAMÁTICA. [S.l.: s.n.]. Disponível em: <https://dicionarioegramatica.com.br/2015/09/29/qual-foi-o-primeiro-dicionario-da-linguaportuguesa/>. Acesso em: 13 out. 2016.

DICIONÁRIO ILUSTRADO TUPI-GUARANI. [S.l.: s.n.]. Disponível em: $<$ http://www.dicionariotupiguarani.com.br/>. Acesso em: 13 out. 2016.

DICIONÁRIO INDÍGENA. [S.l.: s.n.]. Disponível em: $<$ http://dicionarioindigena.blogspot.com.br/>. Acesso em: 13 out. 2016.

DICIONÁRIO INFORMAL. [S.1.: s.n.]. Disponível em: <https://www.dicionarioinformal.com.br/>. Acesso em: 13 out. 2016.

FERREIRA, A. B. de H. Novo dicionário da língua portuguesa. Rio de Janeiro: Nova Fronteira, 1975.

FIGUEIREDO, C. Novo Diccionário da Língua Portuguesa Candido de Figueiredo. Disponível em: <http://www.dicionario-aberto.net/dict.pdf $>$. Acesso em: 13 out. 2016. 
FREIRE, L. Grande e novíssimo dicionário da língua portuguesa. Rio de Janeiro: Livraria José Olympio de Oliveira, 1957.

GARCIA, R. Diccionario de brasileirismos: peculiaridades pernambucanas. Recife: Imprensa Nacional, 1915.

GOMES, D. M. Estudo morfológico e sintático da língua Mundurukú (Tupí). Tese (Doutorado em Linguística). Universidade de Brasília. Brasília, 2006.

HAENSCH, G. Tipología de las obras lexicográficas. In: HAENSCH, G.; WOLF, L.; ETTINGER, S.; WERNER, R. La lexicografía - de la linguística teórica a la lexicografía práctica. Madrid: Gredos, 1982. p. 95-187.

KRIEGER, M. da G. Lexicologia e lexicografia diacrônicas: qual o papel desse tipo de pesquisa? In: ISQUERDO, A. N.; BARROS, L. A. As ciências do léxico: lexicologia, lexicografia, terminologia. Campo Grande: Editora da UFMS, 2010. p. 135-154.

LAROCA, M. N. de C. Manual de morfologia do português. Campinas: Pontes Editora, 1994. MAGALHÃES, M. M. S. Sobre a morfologia e a sintaxe da língua Guajá (FamíliaTupíGuaraní). Tese (Doutorado em Linguística). Universidade de Brasília. Brasília, 2007.

MAIA, M. et al. Comparação de aspectos da gramática em línguas indígenas brasileiras. DELTA: Documentação de estudos em Lingüística teórica e aplicada, v. 14, n. 2, p. 349-375, 1998.

MATTHEWS, P. H. Morphology: an introduction to the theory of word-structure. Cambridge: University Press, 1974.

MURAKAWA, C. de A. A. Dicionário histórico do português do Brasil: problemas e soluções. In: ISQUERDO, A. N.; BARROS, L. A. As ciências do léxico: lexicologia, lexicografia, terminologia. Campo Grande: Editora da UFMS, 2010. p. 237-253.

MURAKAWA, C. de A. A. Lexicografia e História: o Dicionário Histórico do Português do Brasil - séculos XVI, XVII E XVIII. In: ALVES, I. M. et al. Os estudos lexicais em diferentes perspectivas. São Paulo: Editora da FFLCH/USP, 2009.

NASCENTES, A. O linguajar carioca. Rio de Janeiro: Edição da Organização Simões, 1953.

NEVES, M. H. de M. A gramática passada a limpo: conceitos, análises e parâmetros. São Paulo: Parábola Editorial, 2012.

PORTAL DA PALAVRA. iDicionário Aulete. [S.l.: s.n.]. Disponível em: <http://www.portaldapalavra.com.br/o_que_e.php>. Acesso em: 13 out. 2016.

PRIBERAM. Dicionário Priberam da Língua Portuguesa. [S.l.: s.n.]. Disponível em: $<$ https://www.priberam.pt/dlpo/>. Acesso em: 13 out. 2016.

RODRIGUES, A. D. Línguas brasileiras: para o conhecimento das línguas indígenas. São Paulo: Edições Loyola, 1994. 
SAMPAIO, T. O tupi na geographia nacional. Glossario paraense; ou, Collecção de vocabulos peculiares á Amazonia e especialmente á ilha do Marajó, por Vicente Chermont de Miranda. Pará, Livraria Maranhense, 1905 [i.e. 1906].

SEKI, L. Gramática do kamaiurá: Língua tupí-guaraní do alto Xingu. Campinas: Editora da Unicamp, 2000.

SILVA NETO, S. da. Introdução ao estudo de língua portuguêsa no Brasil. Rio de Janeiro: Presença, 1976.

SILVA, A. de M. Diccionario da Lingua Portugueza. [S.l.: s.n.]. Disponível em: $<$ http://dicionarios.bbm.usp.br/pt-br/dicionario/edicao/2>. Acesso em: 13 out. 2016.

SILVA, M. C. P. da. Para uma tipologia geral de obras lexicográficas. In: OLIVEIRA, A. M. P. P. de; ISQUERDO, A. N.; ALVES, I. M. As ciências do léxico: lexicologia, lexicografia, terminologia (3. ed.). Campo Grande: Editora da UFMS; São Paulo: Editora Humanitas, 2001.

SILVA, J. P. O que mudou para os brasileiros com o novo acordo ortográfico da língua portuguesa. In: MOREIRA, M. E.; SMITH, M. M.; BOCCHESE, J. da. C. Novo acordo ortográfico da Língua Portuguesa: questões para além da escrita. Porto Alegre: EdiPUCRS, 2009.

TIMBANE, A. A. A criatividade lexical da língua portuguesa: uma análise com brasileirismos e moçambicanismos. Belo Horizonte: Caligrama, 18(2), p. 7-30, 2003.

VERDELHO, T. Dicionários portugueses, breve história. In: Nunes, J. H., PETTER; M. M. T. História do saber lexical e constituição de um léxico brasileiro. São Paulo: Humanitas; Campinas: Pontes Editores, 2002.

ZANOTTO, N. Estrutura mórfica da língua portuguesa. Caxias do Sul: Educs, 1986. 